\title{
Diverse responses of old, modern and landraces of Syrian wheat genotypes to common root rot under field conditions
}

\author{
M.I.E. Arabi', E. Al-Shehadah' and M. Jawhar ${ }^{1 *}$
}

\begin{abstract}
The yield response of widely grown cultivars and landraces of Syrian wheat challenged with common root rot (CRR: Cochliobolus sativus) was measured by comparing plots with and without artificial inoculation under experimental conditions in two consecutive seasons. The results showed that response to CRR differed depending on the susceptibility levels of the wheat cultivars, and that the disease significantly $(P<0.05)$ reduced grain yield, number of tillers and kernel weight. The diseased plants had fewer tillers which consequently reduced grain yield per plant. Yield losses of Triticum durum cultivars were higher than those of Triticum aestivum. In addition, the T. durum landrace Horani exhibited the best level of resistance to the disease, which indicates that this landrace might be a candidate donor for resistance in future breeding programmes. As CRR can dramatically reduce wheat grain yields under favorable conditions, management practices that reduce disease severity are highly recommended.
\end{abstract}

Additional keywords: Cochliobolus sativus, Triticum aestivum, Triticum durum, yield loss.

\section{Introduction}

Common root rot (CRR), caused by Cochliobolus sativus (Ito \& Kurib.) Drechsl. ex Dast. [anamorph: Bipolarissorokiniana (Sacc. in Sorok.) Shoem.], is an economically important disease of barley, wheat and other small grains in semi-arid climates worldwide (McKayet al., 2018). CRR causes a brown to black discoloration of the subcrown internodes (SCls) of wheat (Triticum aestivum L.), which is directly related to yield losses (Mathre et al., 2003; Fernandez Holzgang, 2009).

Although fungicides can reduce disease severity, the most effective and environmentally sound means of control is through the use of resistant cultivars (Kumar et al., 2002). Wheat interaction with CRR is genotype dependent (Fernandez and Jefferson, 2004) and affected by soil inoculum (Smiley et al., 2005). Therefore, prior to controlling CRR, the potential of this disease to cause losses in wheat growing areas should be evaluated.

The impact of CRR on the crop (wheat) is

\footnotetext{
1 Department of Molecular Biology and Biotechnology, AECS, P. O. Box 6091, Damascus, Syria.

* Corresponding author: ascientific@aec.org.sy
}

important because reductions in plant biomass are a measure of the combined effects of the disease on photosynthesis and other production processes (Fernandez and Conner, 2011). Therefore, this study was carried out to evaluate wheat yield responses to CRR under experimental conditions that are typical of a large part of the wheat-growing areas of western Asia.

\section{Materials and Methods}

\section{Plant material}

Ten most widely grown cultivars and landraces of Syrian wheat were used in the study. They included two Triticum durum landraces (Horani and Salamoni), four Triticum aestivum cultivars (Bouhouth4, Bouhouth6, Cham2 and Doma4), one T. aestivum introduced cultivar (Maksibak) and three T. durum cultivars (Bouhouth7, Cham3 and Doma1).

\section{Seed inoculation}

Nine isolates of $C$. sativus, selected on the basis of cultural and morphological characteristics and virulence (Arabi and Jawhar, 2002), were used. These isolates were obtained from subcrown internodes of bar- 
ley plants showing CRR symptoms. Each isolate was grown on potato dextrose agar (PDA, DIFCO, Detroit, MI, USA) for 10 days at $22 \pm 1{ }^{\circ} \mathrm{C}$ in the dark. After 10-12 days, conidia were collected by flooding the plate with $10 \mathrm{~mL}$ of sterile distilled water and scraping the colony surface with a glass slide to dislodge the conidia. Equal volumes of conidial suspension of each isolate were mixed and filtered through a double layer of cheesecloth. The resulting conidial suspension was adjusted to $5 \times 10^{5}$ conidia/mL.

\section{Experimental design}

The trials were conducted at a site approximately $55 \mathrm{~km}$ south of Damascus for two consecutive years (2016-2017), under natural rainfed conditions $(350 \mathrm{~mm}$ annual rainfall). Seed inoculation was performed according to the method described by van Leur (1991), where, $30 \mathrm{~g}$ seeds of each cultivar were placed in a plastic Petri dish (12$\mathrm{cm}$ in diameter) containing $10 \mathrm{~g}$ sterile neutralized peat, $40 \mathrm{ml}$ spore suspension $(5 \times$ $10^{5}$ condia/ml) and 8 drops of natural Arabic gum. Following thorough agitation for 1 min, the seeds were sown at $6 \mathrm{~cm}$ depth to promote long subcrown internodes (Kokko et al., 1995) in a randomized complete block design, with three replicate plots $(1 \mathrm{~m} \mathrm{x} 1 \mathrm{~m})$ separated with a 1-m wide border. Each plot consisted of five rows, $20 \mathrm{~cm}$ apart and with 50 seeds per row. Based on laboratory preliminary tests on PDA media, CRR-free seeds were used as controls.

\section{Disease evaluation}

Subcrown internodes ( $\mathrm{SCls}$ ) were examined 8 weeks post-inoculation by measuring the percentage of SCls surface showing CRR symptoms using a 0-5 scale, as described by Kokko et al. (1995), where 0 (resistant); 1 = HT (highly tolerant): small light brown lesions covering $1-10 \%$ of the $\mathrm{SCl} ; 2=\mathrm{T}$ (tolerant): light brown lesions covering $11-25 \%$ of the $\mathrm{SCl} ; 3$ = MS (moderately susceptible): light brown/black lesions covering $26-40 \%$ of the $\mathrm{SCl} ; 4=\mathrm{S}$ (susceptible): black lesions covering $41-75 \%$ of the $\mathrm{SCl} ; 5=\mathrm{HS}$ (highly susceptible): black lesions covering $76-100 \%$ of the $\mathrm{SCl}$. 1000-kernel weight (TKW) and yield estimation

Three central rows of each replicate plot were harvested at maturity stage to measure grain yield (gr/plant). A 500 -seed subsample from each row was used to calculate 1000-kernel weight (TKW). The number of tillers per plant was determined on individual hand-harvested plants.

\section{Statistical analysis}

Data was subjected to analysis of variance using the STAT-ITCF statistical programme ( $2^{\text {nd }}$ Version). Differences between means were evaluated for significance by using Newman-Keuls test at 5\% probability level (Anonymous, 1988)

\section{Results and Discussion}

CRR produced brown-dark lesions on SCls, and these symptoms were more severe on the susceptible cultivar Bouhouth7 (Fig. 1). The results are in agreement with our pre-

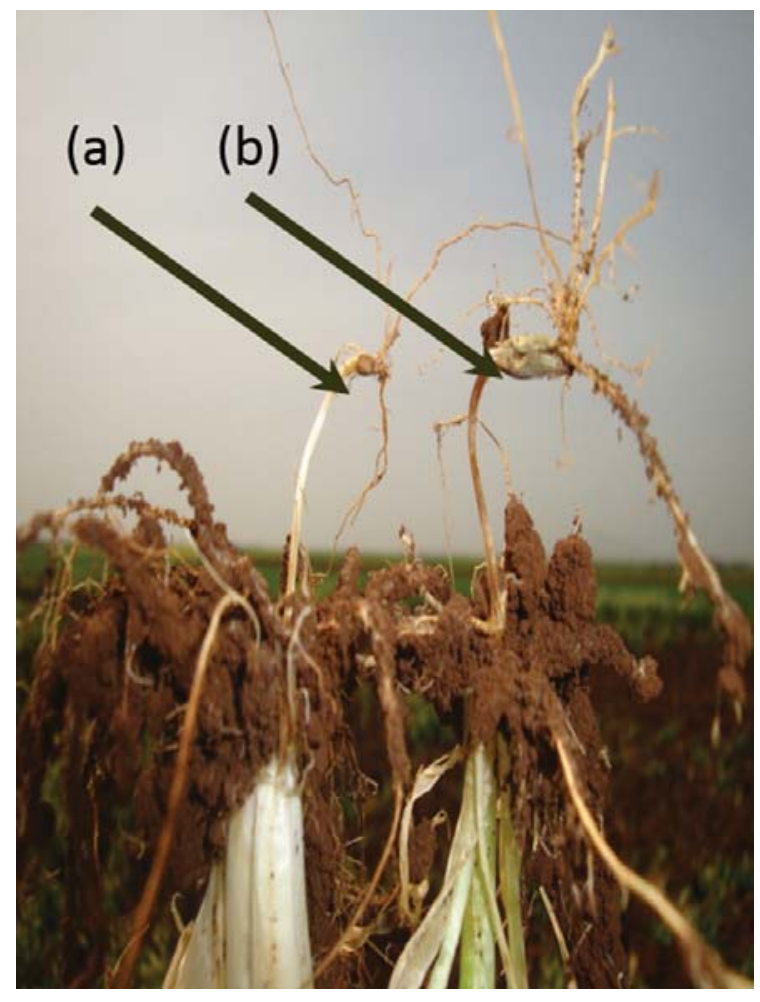

Figure 1. Common root rot symptoms (Cochliobolus sativus)on the wheat (a) highly tolerant landrace 'Horani' and(b) highly susceptible cv. Bouhouth 7, under field conditions. 
vious observations under natural field conditions (Arabi and Jawhar, 2002). The reactions of the 10 wheat cultivars to $C$. sativus are presented in Table 1. Significant differences $(P<0.05)$ in disease severity were detected among cultivars, with values being consistently higher in the susceptible cultivars, in both years of experimentation. In both seasons, landrace Salamoni was highly susceptible with mean disease severity 83.4 $\%$. The T. durum landrace Horani proved to be the most tolerant having $9.9 \%$ disease severity (Table 1). In general, the T. durum cultivars were more tolerant than those of $T$. aestivum (Table 1).

The effects of CRR on grain yield are presented in Table 2. During the first growing season (2016), no significant differences in yield were observed between plants obtained from inoculated and non-inoculated seeds. During the second growing season (2017), grain yield was reduced by CRR in relation to the non-inoculated seeds in all other cultivars except for the highly tolerant landrace Horani.

Moreover, CRR significantly $(P<0.05)$ reduced the TKW of the cvs Bouhouth6 and Maksibak by $18.9 \%$ and $8.6 \%$ in 2016 , and by $14.3 \%$ and $29.5 \%$ in 2017 , respectively
(Table 3). The reduction of TKW in the other cultivars differed greatly depending on the cultivar (Table 3).

As shown in Table 4, the number of tillers decreased significantly $(P<0.05)$ by 28 and $27 \%$ in the cvs Bouhouth 6 and Cham3, in 2016 , and by 37.5 and $39.5 \%$, in 2017, respectively (Table 4). Diseased plants had fewer tillers resulting in reduced grain yield per plant. Similar results were reported by Fernandez et al. (2014) and Duczek and JonesFlory (1993), who found that wheat plants infected by $C$. sativus early in the season produced fewer tillers than those infected later in the season, which was reflected in yield per plant. The current study also showed that the average response of wheat cultivars to CRR differed with the susceptibility level. These findings are in agreement with those of Rush and Mathieson (1990) and Bhandari and Shrestha (2004).

Overall, CRR had a negative effect on TKW and the number of tillers produced in susceptible wheat cultivars grown under rainfed conditions in southern Syria. The reduction in total grain yield may be attributed mainly to the reduction in the number of tillers, as reported by Conner et al. (1996). However, according to Fernandez and Con-

Table 1. Reaction of wheat genotypes to Common root rot (CRR; Cochliobolus sativus) under field conditions in two growing seasons $(2016,2017)$.

\begin{tabular}{|c|c|c|c|c|}
\hline \multirow{2}{*}{ Cultivar } & \multirow{2}{*}{ Origin } & \multicolumn{3}{|c|}{ Severity (\% subcrown internodes infected area) } \\
\hline & & Year 2016 & Year 2017 & Mean effect \\
\hline Horani & Landrace & $A 11.3 d^{y}$ & A8.5d & $9.9 d$ \\
\hline Cham3 & Syrian (Developed by SGCASR)* & A10.3d & A9.2d & 9.7d \\
\hline Doma4 & “ & A11.2d & B15.9d & $13.6 d$ \\
\hline Cham2 & “ & $\mathrm{A} 15.2 \mathrm{~d}$ & B22.5d & $18.9 c$ \\
\hline Doma1 & “ & A31.2C & B17.0d & $24.1 \mathrm{c}$ \\
\hline Bouhouth4 & “ & A33.2C & B27.9C & $30.6 c$ \\
\hline Bouhouth6 & $"$ & A42.6ab & B48.2ab & $45.4 \mathrm{ab}$ \\
\hline Maksibak & Introduced & A66.5ab & B58.9b & $62.7 b$ \\
\hline Bouhouth7 & Syrian (Developed by SGCASR)* & A84.9a & B77.2a & $81.1 a$ \\
\hline Salamoni & Landrace & A82.97a & A84.0a & $83.5 a$ \\
\hline Mean & & A42.11 & B36.92 & \\
\hline
\end{tabular}

y Means (three replicates/cultivar) preceded by different capital letters (row) and followed by different lowercase letters (column) differ significantly at $P<0.05$ according to Newman-Keuls test. ${ }^{*}$ SGCASR: Syrian General Commission of the Agricultural Scientific Research. 
Table 2. Effect of Common root rot (CRR; Cochliobolus sativus) on grain yield in wheat cultivars under field conditions in two growing seasons $(2016,2017)$.

\begin{tabular}{|c|c|c|c|c|}
\hline \multirow{3}{*}{ Cultivar } & \multicolumn{4}{|c|}{ Grain yield (g/plant) } \\
\hline & \multicolumn{2}{|c|}{ Year 2016} & \multicolumn{2}{|c|}{ Year 2017} \\
\hline & Non & Ino. & Non & Ino. \\
\hline Horani & $\mathrm{A} 2.4 \mathrm{C}^{\mathrm{y}}$ & $\mathrm{A} 2.0 \mathrm{C}$ & $\mathrm{A} 18.2 \mathrm{bc}$ & A16.7ab \\
\hline Cham3 & A4.2bc & A4.0bc & $\mathrm{A} 16.7 \mathrm{C}$ & B7.7c \\
\hline Doma4 & A3.6C & A4.6bc & A33.0a & B19.1a \\
\hline Cham2 & A8.2ab & A8.9a & $\mathrm{A} 18.7 \mathrm{bc}$ & B8.7c \\
\hline Doma1 & A4.5bc & A4.7bc & $\mathrm{A} 16.7 \mathrm{bc}$ & B13.6bc \\
\hline Bouhouth4 & $\mathrm{A} 2.9 \mathrm{c}$ & A3.0c & A19.8bc & B12.3bc \\
\hline Bouhouth6 & A5.8bc & A3.8bc & A28.3ab & B11.5bc \\
\hline Maksibak & $\mathrm{A} 2.8 \mathrm{C}$ & A3.2C & A16.9bc & B9.9c \\
\hline Bouhouth7 & A4.8bc & A4.1bc & $\mathrm{A} 18.2 \mathrm{bc}$ & B12.6bc \\
\hline Salamoni & A11.1a & A7.1ab & A25.3abc & B10.4C \\
\hline Mean & A5.03 & A4.5 & A20.9 & B12.9 \\
\hline Mean & \multicolumn{2}{|c|}{ B4.8 } & \multicolumn{2}{|c|}{ A16.6 } \\
\hline
\end{tabular}

y Means (three replicates/cultivar) preceded by different capital letters (row) and followed by different lowercase letters (column) differ significantly at $P<0.05$ according to Newman-Keuls test. Non: Non-inoculated seeds (control), Ino.: Inoculated seeds (Kokko et al., 1995).

Table 3. Effect of Common root rot (CRR; Cochliobolus sativus) on 1000-kernel weight (TKW) of wheat cultivars during two growing seasons $(2016,2017)$.

\begin{tabular}{|c|c|c|c|c|}
\hline \multirow{3}{*}{ Cultivar } & \multicolumn{4}{|c|}{ 1000-kernel weight (g) } \\
\hline & \multicolumn{2}{|c|}{ Year 2016} & \multicolumn{2}{|c|}{ Year 2017} \\
\hline & Non & Ino. & Non & Ino. \\
\hline Horani & A36.0ay & B34.0b & A37.6ab & B34.0b \\
\hline Cham3 & A28.6bc & $\mathrm{A} 27.3 \mathrm{bc}$ & A35.3ab & B27.3bc \\
\hline Doma4 & A34.0ab & A33.0bc & A37.0ab & B30.6bc \\
\hline Cham2 & A28.1bc & A29.0bc & A28.6ab & A28.6bc \\
\hline Doma1 & B39.0a & A40.6a & A41.0a & A38.6a \\
\hline Bouhouth4 & B23.0c & $A 24.6 c$ & $A 29.6 b$ & B24.6C \\
\hline Bouhouth6 & A37.0a & B30.0bc & A35.0ab & B30.0bc \\
\hline Maksibak & A28.0bc & B25.6bc & A36.3ab & B25.6bc \\
\hline Bouhouth7 & B25.6C & $\mathrm{A} 28.3 \mathrm{bc}$ & A32.3ab & B28.3bc \\
\hline Salamoni & B28.6bc & $\mathrm{A} 27.6 \mathrm{bc}$ & A35.3ab & B32.6bc \\
\hline Mean & A30.8 & B28.0 & A35.5 & B30.1 \\
\hline Mean & \multicolumn{2}{|c|}{ B29.7 } & \multicolumn{2}{|c|}{ A32.8 } \\
\hline
\end{tabular}

y Means(three replicates/cultivar) preceded by different capital letters (row) and followed by different lowercase letters (column) differ significantly at $P<0.05$ according to Newman-Keuls test. Non: Non- inoculated seeds (control), Ino.: Inoculated seeds (Kokko et al., 1995).

ner (2011), CRR directly affected the carbon fixation and other physiological processes in wheat leaves by reducing the upward movement of water and nutrients in plants.
CRR had a direct impact on total grain yield of wheat, and therefore, this disease should be considered when managing wheat diseases. Moreover, continued ef- 
Table 4. Effect of Common root rot (CRR; Cochliobolus sativus) on the number of tillers of wheat cultivars during two growing seasons $(2016,2017)$.

\begin{tabular}{l|cc|cc}
\hline \multirow{2}{*}{ Cultivar } & \multicolumn{3}{c}{ Number of tillers/plant } \\
\cline { 2 - 5 } & \multicolumn{2}{|c}{ Year 2016 } & \multicolumn{2}{c}{ Year 2017 } \\
\cline { 2 - 5 } Horani & Non & Ino. & Non & A6.0a \\
Cham3 & A5.6by & A5.6a & B5.3a \\
Doma4 & A6.3ab & B4.6ab & A7.6a & B4.6a \\
Cham2 & A8.0b & B6.3a & B6.3a \\
Doma1 & A5.3b & B4.6ab & A6.6a & B5.0a \\
Bouhouth4 & A5.6b & B5.0ab & A6.6a & B5.6a \\
Bouhouth6 & A6.3ab & B5.6a & A6.3a & B5.3a \\
Maksibak & A5.0b & B3.6b & A8.0a & B5.0a \\
Bouhouth7 & A5.0b & A5.0ab & A6.6a & B5.0a \\
Salamoni & A6.3ab & B5.6a & A6.3a & B5.0a \\
Mean & A7.6a & B6.0a & A7.6a & B4.3a \\
Mean & A6.1 & A5.2 & A6.9a & B5.1a \\
\hline
\end{tabular}

y Means (three replicates/cultivar) preceded by different capital letters (row) and followed by different lowercase letters (column) differ significantly at $\mathrm{P}<0.05$ according to Newman-Keuls test. Non: Non-inoculated seeds (control), Ino.: Inoculated seeds (Kokko et al., 1995).

forts are required to monitor the occurrence of CRR in cereal fields in Syria to develop a better understanding of the potential risk of its establishment and intensification. The highly CRR tolerant landrace Horani can be considered as a promising parent in wheat breeding programmes.

The authors thank the Director General of Atomic Energy Commission of Syria and the Head of Biotechnology Department for their help throughout the period of this research.

\section{Literature Cited}

Anonymous, 1988. STAT-ITCF, Programme, MICROSTA, realized by ECOSOFT, $2^{\text {nd }}$ Version. Institut Technique des cereals et des Fourrages, Paris, $55 \mathrm{pp}$.

Arabi, M.I.E. and Jawhar, M. 2002. Virulence spectrum to barley (Hordeum vulgare L.) in some isolates of Cochliobolus sativus from Syria. Journal of Plant Pathology, 84: 35-39.

Bhandari, D. and Shrestha, S.M. 2004. Intensity of common root rot on wheat genotypes. Nepal Agricultural Research Journal, 5: 46-48.

Conner, R.L., Bailey, K.L. and Kozub, K.L.G.C. 1996.
The effect of common root rot on the yield of resistant and susceptible wheat. Canadian Journal of Plant Science, 76: 869-877.

Duczek, L.J. and Jones-Flory, L.L. 1993. Relationships between common root rot, tillering, and yield loss in spring wheat and barley. Canadian Journal of Plant Pathology, 15:153-158.

Fernandez, M.R. and Conner, R.L. 2011. Root and crown rot of wheat. Prairie Soils and Crops Journal, 4: 151-157.

Fernandez, M.R. and Jefferson, P.G. 2004. Fungal populations in roots and crowns of common and durum wheat in Saskatchewan. Canadian Journal of Plant Pathology, 26: 325-334.

Fernandez, M.R. and Holzgang, G. 2009. Fungal populations in subcrown internodes and crowns of oat crops in Saskatchewan. Canadian Journal of Plant Science, 89: 549-557.

Fernandez, M.R., Fox, S.L., Hucl, P., Singh, A.K., Stevenson, F.C. 2014. Root rot severity and fungal populations in spring common, durum and spelt wheat, and Kamut grown under organic management in western Canada. Canadian Journal of Plant Science, 94:937- 946.

Kokko, E.G., Conner, R.L., Kozub, G.C. and Lee, B. 1995. Effects of common root rot on discoloration and growth of spring wheat root system. Phytopathology, 85: 203-208.

Kumar, J., Schafer, P., Huckelhoven, R., Langen, G., Baltruschat, H., Stein, E., Nagarajan, S. and Kogel, H.K. 2002. Bipolaris sorokiniana, a cereal pathogen of global concern: cytological and 
molecular approaches towards better control. Molecular Plant Pathology, 3: 185-195.

Mathre, D.E., Johnston, R.H. and Grey, W.E. 2003. Diagnosis of common root rot of wheat and barley. Online. Plant Health Progress doi:10.1094/ PHP-2003-0819-01-DG.

McKay, A., Evans, M., Ducray, D.G., Linsell, H.K.L., Garrard, T., Rowe, S., Davies, L., Gupta, V.G., Hollaway, G., Fanning, J., Cook, M. and Simpfendorfer, S. 2018. Cereal root diseases - current status on impact, detection and management. Grains Research and Development Corporation. Barton, ACT, Australia (GRDC).

Rush, C.M. and Mathieson, J.T. 1990. Effects of common root rot on winter wheat forage production. Plant Disease, 74: 982-985.
Smiley, R.W., Gourlie, J.A., Easley, S.A. and Patterson, L.M. 2005. Pathogenicity of fungi associated with the wheat crown rot complex in Oregon and Washington. Plant Disease, 89: 949-957.

van Leur, J.G. 1991. Testing barley for resistance to Cochliobolus sativus at ICARDA, Syria. In: R. D. Tinline et al. (eds), Proceeding of the $1^{\text {st }} / n t e r n a-$ tional workshop on common root rot of cereals. Saskatoon, p. 128-134.

Received: 14 August 2018; Accepted: 16 May 2019

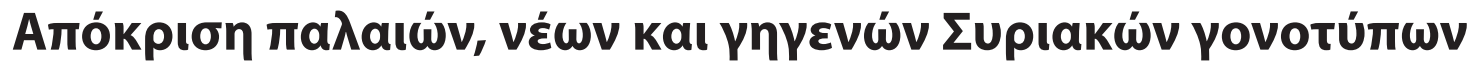

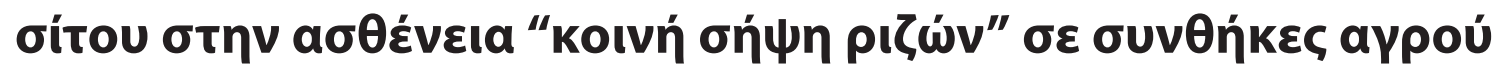

\author{
M.I.E. Arabi, E. Al-Shehadah kaı M. Jawhar
}

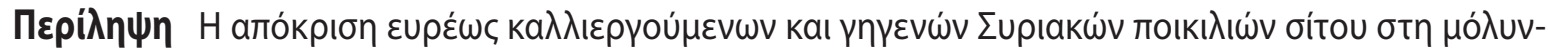

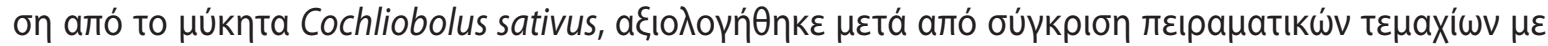

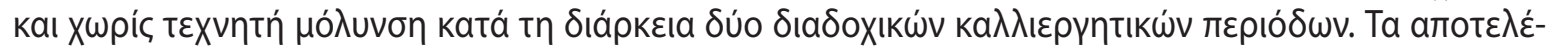

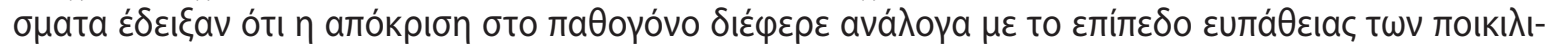

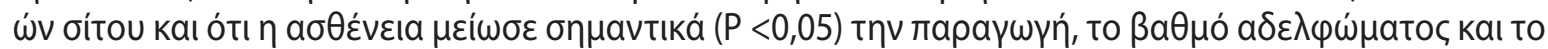

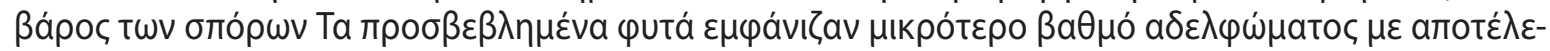

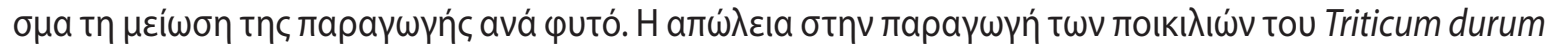

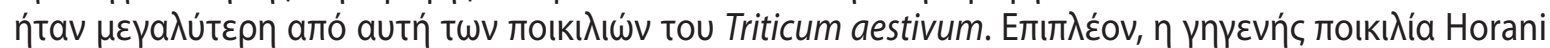

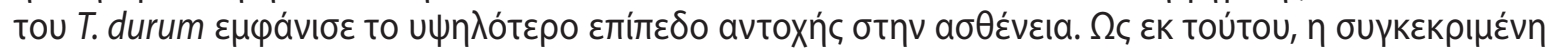

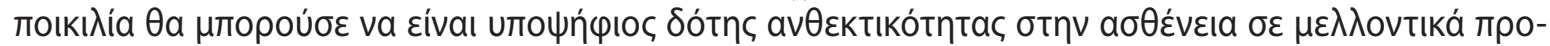

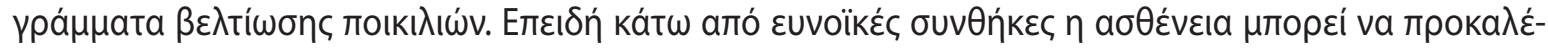

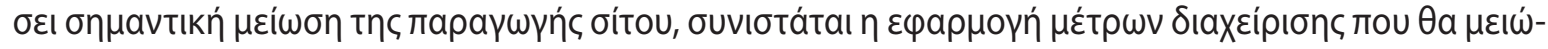

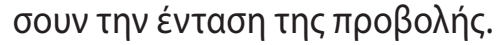

Hellenic Plant Protection Journal 12: 91-96, 2019 